\title{
The Effects of Parenting Style on Emerging Adulthood Emotional Self-Regulation and Identity Development
}

\author{
Merari Flores Saldana \\ University of Florida
}

Faculty Mentor: Larry Forthun, Department of Family, Youth, and Community Sciences

\begin{abstract}
The purpose of this research is to examine how parenting profiles, identity development, and emotional self-regulation may relate to one another in emerging adulthood utilizing a person-centered approach. The data being used for this study was from the Multi-Site University Study of Identity and Culture (MUSIC), which was collected using a cross-sectional online survey. The data consists of 3,775 students of which $61.9 \%$ were White and $69.9 \%$ were females ages $18-29$. A hierarchical cluster analysis was performed for all participants using mother and father psychological control and nurturance to identify the parenting profiles. A four-cluster solution was most parsimonious and consistent after evaluating the agglomeration table and plots. Clusters were finalized using k-means cluster analysis; differences were tested through an analysis of variance (ANOVA) with Games-Howell post hoc testing. Parental Nurturance has high nurturance and low levels of psychological control from both parents. Parental Repression has high levels of psychological control and low levels of nurturance from both parents. Parental Equivocation has high levels of both parental nurturance and psychological control. Maternal Mitigation has high levels of maternal nurturance and paternal psychological control, and low levels of maternal psychological control and paternal nurturance. Parental Nurturance had the highest levels of depth and breadth of exploration, identification with commitment and commitment making, and use of reappraisal. The Maternal Mitigation profile was similar in outcomes. The Parental Equivocation and Parental Repression profiles were significantly lower on identity commitment and reappraisal and significantly higher on ruminative exploration and suppression.
\end{abstract}

Keywords: parenting profiles, emerging adulthood, identity development, emotional selfregulation

\section{Introduction}

Emerging adulthood is an ambiguous stage of life characterized by independent exploration and instability with love, work, and place of residence (Arnett, 2015). While there is considerable research on the process of identity development during adolescence, how this affects them emotionally, and the various ways parenting may affect them (Erikson, 1950; Garcia \& Serra, 2019), there is insufficient research on emerging adulthood and how parenting style may affect both emotional and identity development in this stage (Nelson et al., 2011). The 
purpose of this research is to examine how parenting may affect emotional self-regulation and identity development in emerging adults between the ages of 18 and 29.

\section{Conceptual Overview}

Baumrind (1971) developed three styles of parenting based on levels of behavioral control and warmth with children in early childhood. Authoritarian parenting involves high levels of behavioral control with low levels of warmth, authoritative parenting demonstrates the opposite, and permissive parenting has warmth but low control. However, the way in which parenting applies in emerging adulthood, ages of 18 through 29, may differ compared to childhood and adolescence. For example, research shows that psychological control is more frequent and prevalent compared to behavioral control since emerging adults may be residing elsewhere for work and post-secondary education (Arnett, 2015). According to Barber (1996), behavioral control is the parental behavior towards their children, while psychological control is the manipulation parents inflict on their children through insults, withdrawal of love, and invalidation. Likewise, based on emerging adulthood research, nurturance is more prevalent compared to warmth due to the physical absence of parents. Warmth requires physical affection and attention; whereas, nurturance involves parental responsiveness, respect towards their child's independent decisions, and knowledge of their child's life (Baumrind, 1971; Finley, Mira, \& Schwartz, 2004; Nelson et al., 2011).

According to Arnett (2015), identity development is imperative. Erikson's (1950) fifth stage of the psychosocial development theory, identity versus role confusion, states that adolescents experiment with different roles and experiences. Otherwise, adolescents experience role confusion, or insecurity about themselves and their future. However, Arnett (2015) argues that this process is crucial for emerging adults to explore and make commitments to career choices and beliefs. Marcia (1966) observed that there are two important identity processes, identity exploration and commitment, which form four different identity statuses: identity achievement (exploration then commitments), identity foreclosure (commitments with no exploration), identity moratorium (exploration with no commitments), and identity diffusion (neither exploring nor committed).

Beyers and Luyckx (2016) expanded this model and further identified three types of exploration and two types of commitment. Ruminative exploration consists of constant worrying and indecisiveness, which is associated with negative externalizing behavior and weak 
commitment (Beyers \& Luyckx, 2016). Depth and breadth of exploration include seeking and testing commitments and is associated with strong commitment and negatively associated with internalizing and externalizing problems (Beyers \& Luyckx, 2016). Commitment making refers to the degree of confidence in plans and perception of the future, while identification with commitments refers to the security of plans and the future (Beyers \& Luyckx, 2016). To manage the negative consequences that may occur with identity development and instability emerging adulthood, another important factor to examine in emerging adulthood is emotional selfregulation (Arnett, 2015). Gross and John (2003) proposed two forms of emotional selfregulation. In cognitive reappraisal, individuals change their mindset from negative to positive; with suppression, emotions are internalized and avoided.

\section{Review of Literature}

Evidence suggests that both maternal and paternal caregiving influences identity development and emotion self-regulation in emerging adulthood. Luyckx, Soenens, Vansteenkiste, Goossens, and Berzonsky (2007) found that when emerging adults perceive parents as psychologically controlling, identity commitments decrease (Luyckx et al., 2007). Likewise, Gomes Cordeiro, Paixão, Lens, Lacante, and Luyckx (2018) found that high levels of parental psychological control lead to feelings of isolation, pressure, and self-doubt in emerging adults. Autonomy provides security for exploration for emerging adults (Zong et al., 2019), and perceived autonomy support from both parents leads to exploration in breadth of new roles, exploration in-depth of current commitments, and identification with commitments (Beyers \& Goossen, 2008; Zong et al., 2019). However, Beyers and Goossen (2008) found that mothers are more autonomy supportive, discourage exploration in breadth, and encourage their child to make commitments more than fathers.

Parental psychological control and nurturance also play a role in emotional self-regulation in emerging adulthood. When both parents demonstrate responsiveness and democracy, emerging adults are more emotionally adjusted and have higher self-esteem. (McKinney \& Renk, 2008). If one parent demonstrates high demandingness or psychological control, emotional regulation is negatively influenced; for example, emerging adults reported low levels of emotional adjustment when mothers had high control and fathers had low control (McKinney \& Renk, 2008). However, if only the father expressed high control, emerging adults had moderately better emotional adjustment (McKinney \& Renk, 2008). This points to the greater influence maternal 
parenting has, which may due to their level of involvement and awareness of their child's emotional state even while away (Rodriguez, Tucker, \& Palmer, 2016).

\section{Current Study}

Based on the empirical research on emerging adulthood, parenting style continues to affect identity development and emotion self-regulation. Both maternal and paternal psychological control are risk factors to negative consequences that affect career decision making, commitment making, and exploration (Gomes Cordeiro et al., 2018; Luyckx et al., 2007), and when both parents demonstrate lower levels of control and higher levels of nurturance, emerging adults report better emotional regulation (McKinney \& Renk, 2008; Manzeske \& Dopkins, 2009). Maternal parenting seems to be of greater influence than paternal in both psychological control and nurturance; however, having at least one parent that shows nurturance seems to result in positive emotional self-regulation for emerging adults (Manzeske \& Dopkins Stright, 2009; McKinney \& Renk, 2008; Rodriguez et al., 2016).

While this evidence exists, there continues to be a gap in knowledge on how parenting may influence identity development and emotional self-regulation in emerging adults. A personcentered analysis of the parent-child relationship was conducted to examine the perceptions of parenting for mothers and fathers (Magnusson \& Stattin, 2006). It was expected that parenting characteristics would likely generate two or more parenting clusters. Previous research would suggest the following hypotheses

Hypothesis 1. Profiles consisting of high nurturance will be related to a higher use of cognitive reappraisal, in-depth and breadth exploration, commitment, and low rumination.

Hypothesis 2. Parenting profiles consisting of high psychological control will be related to a higher use of suppression and rumination, and low in-depth and breadth exploration and commitment.

\section{Methods}

\section{Participants}

The current study utilized secondary data from the Multi-Site University Study of Identity and Culture (MUSIC) with a representative sample of college students in the U.S. from 2009 (Castillo \& Schwartz, 2013). Table 1 summarizes the demographic characteristics of the participants between the ages of 18 and 29 , resulting in a final sample of 3,775 students. The 
mean age of respondents was 19.96 years, $29.6 \%$ of respondents chose to identify their sex as male, $69.9 \%$ as female. Most participants classified themselves as White (61.9\%), with $14.6 \%$ as East Asian, $10.8 \%$ as Hispanic, $6.1 \%$ as Black, $4.0 \%$ as South Asian, 1.7\% as Middle Eastern, and $.1 \%$ as Colored-South African. Most were in their first (37.4\%) or second (22.8\%) year of college and reported that their parents were still married (70.3\%) (see Table 1).

\section{Sampling and Data Collection Procedures}

Students from various academic departments in 20 colleges and universities across the U.S. were recruited with the assistance of course instructors who offered extra credit. To participate, students had to be at least 18 years old to give legal consent and be an undergraduate student. Participants completed a survey online and had the option to save and finish later if necessary. 
Table 1. Demographics of Participants of the Year 2009

\begin{tabular}{|c|c|c|}
\hline Demographics & Frequency & Percent \\
\hline \multicolumn{3}{|l|}{ Age } \\
\hline 18 & 995 & 22.9 \\
\hline 19 & 1177 & 27.1 \\
\hline 20 & 821 & 18.9 \\
\hline 21 & 665 & 15.3 \\
\hline 22 & 312 & 7.2 \\
\hline 23 & 147 & 3.4 \\
\hline 24 & 73 & 1.7 \\
\hline 25 & 49 & 1.1 \\
\hline 26 & 34 & .8 \\
\hline 27 & 22 & .5 \\
\hline 28 & 28 & .6 \\
\hline 29 & 13 & .3 \\
\hline Missing & 0 & 0 \\
\hline \multicolumn{3}{|l|}{ Gender } \\
\hline Male & 1272 & 29.3 \\
\hline Female & 3037 & 70.0 \\
\hline Missing & 27 & .6 \\
\hline \multicolumn{3}{|l|}{ Ethnicity } \\
\hline Black & 280 & 6.5 \\
\hline White & 2631 & 60.7 \\
\hline East Asian & 635 & 14.6 \\
\hline Hispanic & 498 & 11.5 \\
\hline South Asian & 177 & 4.1 \\
\hline Middle Eastern & 75 & 1.7 \\
\hline Colored-South African & 3 & .1 \\
\hline Missing & 37 & .9 \\
\hline \multicolumn{3}{|l|}{ Years in College } \\
\hline 1 & 1610 & 37.1 \\
\hline 2 & 980 & 22.6 \\
\hline 3 & 899 & 20.7 \\
\hline 4 & 485 & 11.2 \\
\hline 5 & 145 & 3.3 \\
\hline 6 and more years & 68 & 1.6 \\
\hline Missing & 149 & 3.4 \\
\hline \multicolumn{3}{|l|}{ Family Form } \\
\hline Intact & 2999 & 69.2 \\
\hline Separated/Divorced & 777 & 17.9 \\
\hline Stepfamily & 87 & 2.0 \\
\hline Never Married & 133 & 3.1 \\
\hline Other & 17 & .4 \\
\hline Missing & 323 & 7.4 \\
\hline
\end{tabular}




\section{Measures}

Emerging adults were asked to respond to the parenting questions based on the individual in their life who they identified as the most important mother figure and father figure. In the survey, paternal and maternal caregivers may not represent their biological parents. Table 2 summarizes the parenting variables' descriptive statistics and reliability measures.

paternal and maternal nurturance. The Paternal and Maternal Nurturance Scale, created by Finley, Mira, and Schwartz (2004) was used to measure the perceived maternal and paternal emotional support given to the child with 9 items for each caregiver and measured at the ordinal level with a Likert scale of 1 (never) to 5 (always). The scale score was created utilizing the mean scores of respondents for the level of nurturance. None of the items were reversed scored. The Nurturance scales were reliable with a Cronbach's alpha $(\alpha)$ of .953 for Paternal Nurturance and an $\alpha$ of .941 for Maternal Nurturance (see Table 2).

paternal and maternal psychological control. Paternal and maternal psychological control was measured utilizing the Psychological Control Scale from Barber (1996) which measures perceptions of whether parents try to change how the child thinks or topics of discussion, if their parents blamed them and criticized them, and if their parents ignored them. This variable was measured at the ordinal level with a Likert scale of 1 (strongly disagree) to 5 (strongly agree) with 8 items for each parent figure. None of the items were reverse scored. Paternal psychological control resulted in an $\alpha$ of .898, and maternal psychological with an $\alpha$ of .901 (see Table 2).

Table 2. Mean, Standard Deviation, and Reliability of Measures of Parenting Variables

\begin{tabular}{lccc}
\hline Parenting Variables & Mean & SD & $\begin{array}{l}\text { Cronbach's } \\
\text { Alpha }\end{array}$ \\
\hline Paternal Nurturance & 3.60 & 1.074 & .953 \\
Paternal Psychological Control & 1.99 & .883 & .898 \\
Maternal Nurturance & 4.20 & .831 & .941 \\
Maternal Psychological Control & 1.96 & .909 & .901 \\
\hline
\end{tabular}


emerging adult identity development. Identity development was measured using the Dimensions of Identity Development Scale created by Luyckx et al. (2008), with 25 items at the ordinal level with a Likert scale of 1 (strongly disagree) to 5 (strongly agree). Table 3 summarizes the emerging adult variables' descriptive statistics and reliability measures. Participants responded to five items on their confidence in their plans and perception for the future to measure commitment making $(\alpha=.921)$. Four items measured participants' identification with commitment on how their plans would make them feel secure of their future $(\alpha$ $=.928$ ). Four items measured exploration in breadth on whether they spent time thinking about their plans and intended lifestyle in future $(\alpha=.844)$. Participants responded to four items about their thoughts and evaluation of their plans and engagement with others to measure exploration in-depth $(\alpha=.809)$. Four items measured ruminative exploration on participants' prolonged, doubtful, and worrisome thinking about their future $(\alpha=.838)$. None of the items were reversed scored.

Table 3. Mean, Standard Deviation, and Reliability of Measures of Identity Development and Emotional Self-Regulation Variables

\begin{tabular}{lccc}
\hline Measured Variables & Mean & SD & $\begin{array}{c}\text { Cronbach's } \\
\text { Alpha }\end{array}$ \\
\hline Commitment Making & 3.79 & .899 & .921 \\
Identification with Commitment & 3.81 & .904 & .928 \\
Exploration in Breadth & 3.98 & .762 & .844 \\
Exploration in Depth & 3.76 & .748 & .809 \\
$\begin{array}{l}\text { Ruminative Exploration } \\
\text { Emotional Self-Regulation }\end{array}$ & 3.11 & .943 & .838 \\
$\begin{array}{l}\text { Reappraisal } \\
\text { Emotional Self-Regulation }\end{array}$ & 4.84 & 1.133 & .883 \\
Suppression & 3.60 & 1.212 & .777 \\
\hline
\end{tabular}

emerging adult emotional self-regulation. Emotional self-regulation was measured using the Emotional Regulation Questionnaire from Gross and John (2003) which assesses one's 
behavior and thought process when faced with a distressful situation. Ten items were used to measure this at an ordinal level with a Likert scale of 1 (strongly disagree) to 7 (strongly agree). Six items measured cognitive reappraisal, defined as the way in which one changes negative thoughts into positive ones $(\alpha=.883)$. Four items measured suppression, defined as controlling emotions by not expressing them $(\alpha=$.777). None of the items were reverse scored.

\section{Analysis}

Preliminary analysis was performed to ensure no violation of the assumptions of normality, linearity, and homoscedasticity. No violations were determined. The relationship between parenting characteristics, identity development, and emotional self-regulation factors were initially investigated using Pearson product-moment correlation coefficient. Due to the large population sample, only correlation coefficients above .10 were considered an interpretable effect size (Cohen, 1988). Next, parenting profiles were formed using a two-step cluster analysis procedure. First, a hierarchical cluster analysis was performed on mother and father psychological control and nurturance using the Ward method of agglomeration with squared Euclidean distance (Ward, 1963). Based on an evaluation of the agglomeration coefficients and plots, there were between three and five possible clusters (Henry, Tolan, \& Gorman-Smith, 2005). Five clusters had two groups that were very similar. Three clusters ruled out a distinct cluster where there was a significant difference in maternal and paternal characteristics; therefore, a four-cluster solution was most parsimonious. Cluster centers were identified in the hierarchical procedure and input into a k-means cluster procedure (Henry et al., 2005).

A one-way between groups analysis of variance (ANOVA) was conducted to explore differences in means scores for the emerging adult variables on the four parenting profiles. Levene's test of equality of variances across groups was significant for each of the emerging adult variables. To correct for this violation of the assumption, the Welch test was used in place of the F-test (Pallant, 2016). In addition, post hoc analysis was performed using the GamesHowell test, which is more robust to violations of this assumption (Ramsey \& Ramsey, 2009).

\section{Results}

\section{Pearson Correlation Results}

Table 4 shows the results of the Pearson correlation analysis performed with each of the variables included in the study. For the parenting variables, paternal and maternal psychological control were each negatively correlated with paternal and maternal nurturance, as expected from 
previous research (Nelson et al., 2011). Between the parenting and identity development variables, paternal and maternal nurturance were positively correlated with exporation in-depth, commitment making, and identification with commitments. Maternal nurturance was positively correlated with exploration in breadth and cognitive reappraisal. Paternal and maternal psychological control were each negatively related to identification with commitment and commitment making and positively related to ruminative exploration. Maternal psychological control was positively related to suppression.

\section{Cluster Analysis Results}

The differences between the profiles from the ANOVA analysis, which were derived from the two-step cluster analysis, are shown in Table 5 and represented in Figure 1. Clusters were labelled after the levels of psychological control, nurturance, and their influence on emerging adults. Parental Nurturance was named after its high paternal and maternal nurturance. Parental Repression was labelled because of the high parental psychological control, which would repress emerging adult development. Parental Equivocation was named after the perceived confusion emerging adults may experience from the high parental nurturance and psychological control. Maternal Mitigation was labelled from the high maternal nurturance mitigating the moderate paternal psychological control. 
Table 4. Pearson's R Matrix of Correlations of Variables

$\begin{array}{lllllllll}1 . & 2 . & 3 . & 4 . & 5 . & 6 . & 7 . & 8 . & 9 .\end{array}$

\section{Paternal}

Nurturance

2. Paternal - $-.422 *$

Psych Control

3. Maternal $.394 * \quad-.269 *$

Nurturance

4. Maternal $-.250 * \quad .547 *-.492 *$

Psych Control

5.Commitment $.127 * \quad-.098^{*} \quad .182 * \quad-.118^{*}$

Making

6.Identification $\quad .128^{*} \quad-.111^{*} \quad .213^{*} \quad-.121^{*} \quad .859^{*}$

with

Commitment

7. Exploration $\quad .094 * \quad-.089 * \quad .187 * \quad-.091 * \quad .303 * \quad .371 *$

in Breadth

$\begin{array}{llllllll}\text { 8. Exploration } & .103 * & -.054 * & .174 * & -.057 * & .406 * & .460 * & .694 *\end{array}$

in Depth

$\begin{array}{lllllllll}\text { 9. Ruminative } & -.028 & .132 * & -.024 & .138 * & -.424 * & -.378 * & .292 * & .215 *\end{array}$

Exploration

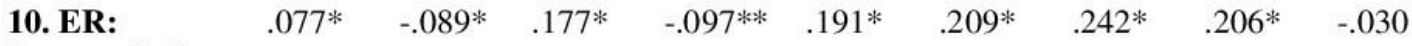

Reappraisal

11. ER: Suppression

$* \mathrm{p}<.01$ 
Table 5. ANOVA Results for Parenting Profiles

\begin{tabular}{|c|c|c|c|c|c|c|c|c|c|c|}
\hline \multirow[t]{2}{*}{ Variable } & \multicolumn{2}{|c|}{$\begin{array}{c}\text { Parental } \\
\text { Nurturance }\end{array}$} & \multicolumn{2}{|c|}{$\begin{array}{l}\text { Maternal } \\
\text { Mitigation }\end{array}$} & \multicolumn{2}{|c|}{$\begin{array}{c}\text { Parental } \\
\text { Equivocation }\end{array}$} & \multicolumn{2}{|c|}{$\begin{array}{l}\text { Parental } \\
\text { Repression }\end{array}$} & \multirow[t]{2}{*}{ Welch's F } & \multirow[t]{2}{*}{ Eta $^{2}$} \\
\hline & Mean & SD & Mean & SD & Mean & SD & Mean & SD & & \\
\hline $\begin{array}{c}\text { Paternal } \\
\text { Nurturance }\end{array}$ & $4.35^{\mathrm{a}}$ & .489 & $2.28^{b}$ & .687 & $3.96^{c}$ & .546 & $2.42^{\mathrm{d}}$ & .761 & $2444.853 *$ & .699 \\
\hline $\begin{array}{c}\text { Paternal } \\
\text { Psych Control }\end{array}$ & $1.39^{\mathrm{a}}$ & .367 & $2.21^{\mathrm{b}}$ & .916 & $2.41^{\mathrm{c}}$ & .751 & $2.90^{\mathrm{d}}$ & .851 & $1046.762 *$ & .425 \\
\hline $\begin{array}{l}\text { Maternal } \\
\text { Nurturance }\end{array}$ & $4.61^{\mathrm{a}}$ & .431 & $4.39^{b}$ & .518 & $4.10^{c}$ & .648 & $2.87^{\mathrm{d}}$ & .891 & $734.032 *$ & .498 \\
\hline $\begin{array}{c}\text { Maternal } \\
\text { Psych Control }\end{array}$ & $1.32^{\mathrm{a}}$ & .348 & $1.63^{\mathrm{b}}$ & .533 & $2.74^{\mathrm{c}}$ & .672 & $3.10^{\mathrm{d}}$ & .784 & $1842.794 *$ & .639 \\
\hline
\end{tabular}

Means with differing letters are significantly different from one another based on Games-Howell posthoc analyses $* \mathrm{p}<.001$

\section{Parenting Profiles}

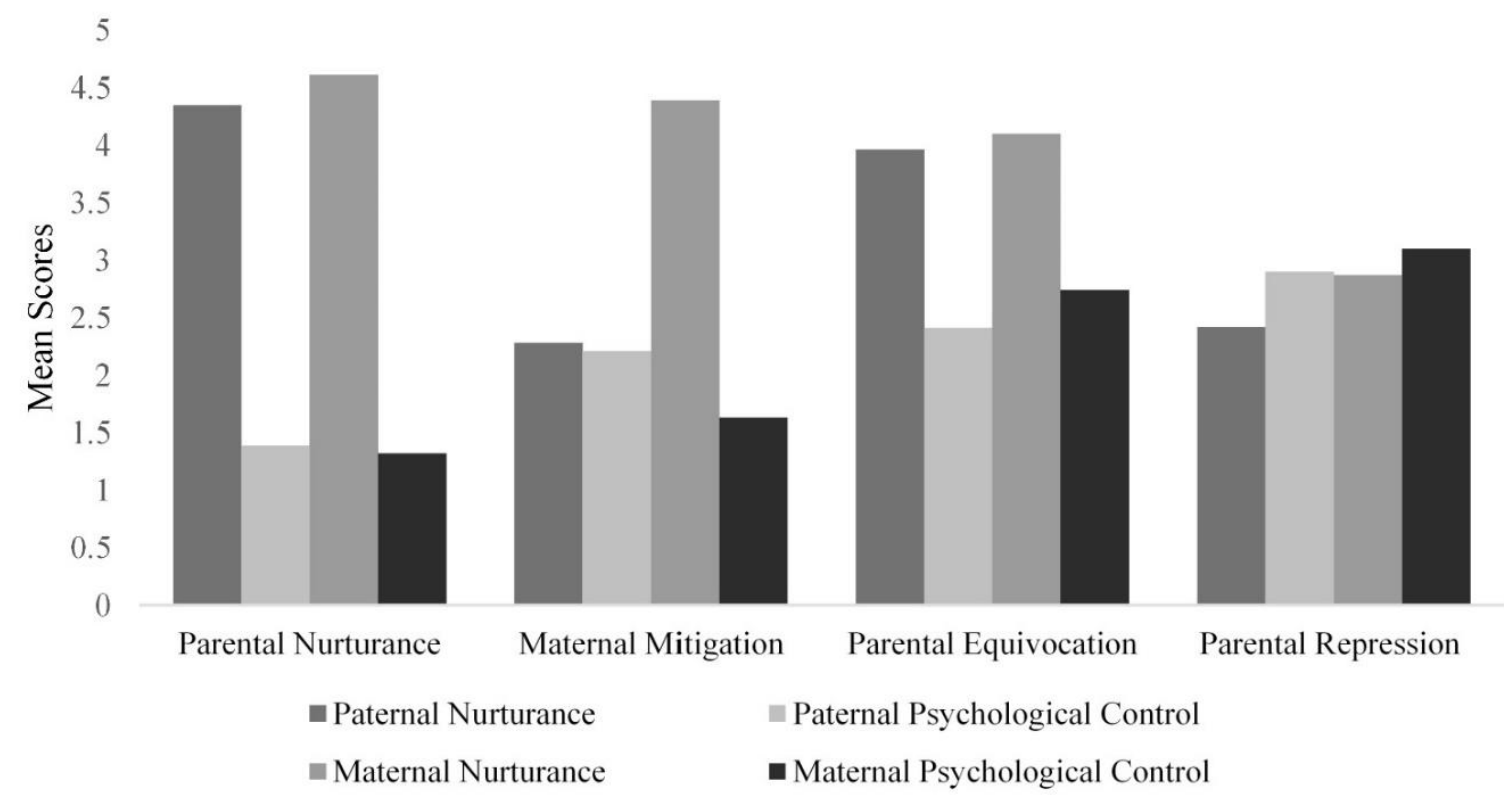

Figure 1. Parenting Profiles with Mean Scores of Parental Nurturance and Psychological Control 


\section{Hypothesis Testing of Identity Development and Emotional Self-Regulation}

identity development. Table 6 demonstrates the ANOVA results comparing the parenting profiles to the identity development variables. Significant differences emerged for Commitment making (Welch $=34.67(3,1503), \mathrm{p}<.001)$, Identification with commitment $($ Welch $=37.01(3,1491), \mathrm{p}<.001)$, exploration in-depth $($ Welch $=15.23(3,1499), \mathrm{p}<.001)$, and exploration in breadth (Welch $=19.51(3,1466), \mathrm{p}<.001)$. The Parental Nurturance profile, characterized by high nurturance and low psychological control, had the highest mean scores for commitment making, identification with commitment, and exploration in-depth. The Parental Repression profile had the lowest mean scores. The Maternal Mitigation and Parental Equivocation profiles, both characterized by high maternal nurturance, were not significantly different from one another, but were significantly different from the other two profiles.

Table 6. ANOVA Results for Emerging Adult Identity Development

\begin{tabular}{|c|c|c|c|c|c|c|c|c|c|c|}
\hline \multirow[t]{2}{*}{ Variable } & \multicolumn{2}{|c|}{$\begin{array}{c}\text { Parental } \\
\text { Nurturance }\end{array}$} & \multicolumn{2}{|c|}{$\begin{array}{l}\text { Maternal } \\
\text { Mitigation }\end{array}$} & \multicolumn{2}{|c|}{$\begin{array}{c}\text { Parental } \\
\text { Equivocation }\end{array}$} & \multicolumn{2}{|c|}{$\begin{array}{c}\text { Parental } \\
\text { Repression }\end{array}$} & \multirow[t]{2}{*}{ Welch $F$} & \multirow[t]{2}{*}{ Eta $^{2}$} \\
\hline & Mean & $\mathrm{SD}$ & Mean & $\mathrm{SD}$ & Mean & SD & Mean & $\mathrm{SD}$ & & \\
\hline $\begin{array}{l}\text { Commitment } \\
\text { Making }\end{array}$ & $3.95^{\mathrm{a}}$ & .882 & $3.78^{\mathrm{b}}$ & .933 & $3.71^{\mathrm{b}}$ & .844 & $3.52^{\mathrm{c}}$ & .925 & $34.671 *$ & .028 \\
\hline $\begin{array}{l}\text { Identification } \\
\text { with } \\
\text { Commitment }\end{array}$ & $3.95^{\mathrm{a}}$ & .887 & $3.81^{\mathrm{b}}$ & .955 & $3.73^{\mathrm{b}}$ & .815 & $3.48^{c}$ & .969 & $37.015^{*}$ & .032 \\
\hline $\begin{array}{l}\text { Exploration } \\
\text { in Breadth }\end{array}$ & $4.08^{\mathrm{a}}$ & .726 & $3.99^{\mathrm{ab}}$ & .757 & $3.93^{\mathrm{b}}$ & .727 & $3.78^{c}$ & .884 & $19.512 *$ & .018 \\
\hline $\begin{array}{l}\text { Exploration } \\
\text { in Depth }\end{array}$ & $3.84^{\mathrm{a}}$ & .748 & $3.73^{b}$ & .762 & $3.73^{\mathrm{b}}$ & .693 & $3.59^{c}$ & .805 & $15.237 *$ & .013 \\
\hline $\begin{array}{l}\text { Ruminative } \\
\text { Exploration }\end{array}$ & $3.00^{\mathrm{a}}$ & .963 & $3.10^{\mathrm{a}}$ & .972 & $3.23^{\mathrm{b}}$ & .883 & $3.24^{\mathrm{b}}$ & .921 & $16.601 *$ & .013 \\
\hline
\end{tabular}

Means with differing letters are significantly different from one another based on Games-Howell posthoc analyses $* \mathrm{p}<.001$ 
For exploration in breadth, the Parental Nurturance and Maternal Mitigation profiles had the highest mean scores compared to the other profiles, and were not significantly different from one another. For ruminative exploration, there was a statistically significant difference between the mean scores for some the parenting profiles $($ Welch $=16.60(3,1523), \mathrm{p}<.001)$. Parental Repression had the highest mean score for ruminative exploration but was not significantly different from Parental Equivocation; both were significantly different from the other two profiles. Parental Nurturance had the lowest mean score but was not significantly different from Maternal Mitigation.

emotional self-regulation. As seen in table 7, the ANOVA results comparing the parenting profiles to the emotional self-regulation variables, for reappraisal for emotional self-regulation there was a statically significant difference between the mean scores on some of the parenting profiles $($ Welch $=22.02(3,1500), \mathrm{p}<.001)$. Parental Nurturance had the highest mean score but was not significantly different from Maternal Mitigation. The Parental Equivocation and Parental Repression profiles were significantly lower for ruminative exploration with Parental Repression with the significantly lowest mean score. For suppression for emotional self-regulation, there was a statically significant difference between the mean scores for some of the parenting profiles $($ Welch $=42.06(3,1506), \mathrm{p}<.001)$. Parental Nurturance and Maternal Mitigation had the lowest mean scores, with both profiles significantly different from one another. Parental Repression was not significantly different from Parental Equivocation, each having the highest mean scores.

Table 7. ANOVA Results for Emotional Self-Regulation

\begin{tabular}{lcccccccccc}
\hline \multicolumn{1}{c}{ Variable } & $\begin{array}{c}\text { Parental } \\
\text { Nurturance }\end{array}$ & \multicolumn{2}{c}{$\begin{array}{c}\text { Maternal } \\
\text { Mitigation }\end{array}$} & $\begin{array}{c}\text { Parental } \\
\text { Equivocation }\end{array}$ & $\begin{array}{c}\text { Parental } \\
\text { Repression }\end{array}$ & Welch $\boldsymbol{F}$ & Eta $^{2}$ \\
& Mean & SD & Mean & SD & Mean & SD & Mean & SD & & \\
\hline $\begin{array}{l}\text { ER: } \\
\text { Reappraisal }\end{array}$ & $4.97^{\mathrm{a}}$ & 1.139 & $4.90^{\mathrm{a}}$ & 1.097 & $4.76^{\mathrm{b}}$ & 1.010 & $4.51^{\mathrm{c}}$ & 1.254 & $22.023^{*}$ & .020 \\
& & & & & & & & & & \\
$\begin{array}{l}\text { ER: } \\
\text { Suppression }\end{array}$ & $3.39^{\mathrm{a}}$ & 1.201 & $3.55^{\mathrm{b}}$ & 1.275 & $3.83^{\mathrm{c}}$ & 1.114 & $3.93^{\mathrm{c}}$ & 1.196 & $42.064^{*}$ & .033 \\
& & & & & & & & & &
\end{tabular}

Means with differing letters are significantly different from one another based on Games-Howell posthoc analyses $* \mathrm{p}<.001$ 


\section{Discussion}

Emerging adulthood is a distinct stage in life involving ambivalence and constant exploration for identity development, which requires emotional self-regulation (Arnett, 2015; Gross \& John, 2003; Marcia, 1966). Most emerging adults are living away from home in this stage, which may challenge the role of parenting. This study focused on how two dimensions of parenting, psychological control and nurturance, affect emerging adult identity development and emotional self-regulation from a person-centered approach.

It was hypothesized that parenting profiles with high nurturance would result in positive identity exploration, commitment, use of cognitive reappraisal, and lower rumination. This hypothesis was partially supported. Parenting profiles with high nurturance were related to positive outcomes, more so for the Parental Nurturance profile where both parents were high in nurturance and low in psychological control which coincided with the literature. When both parents are perceived as nurturing, emerging adults feel confident to explore roles in-depth, commit, and utilize cognitive reappraisal to cope (Beyers \& Goossen, 2008; McKinney \& Renk, 2008; Rodriguez et al., 2016; Zong et al., 2019).

One finding that stood out from this research is that if one parent demonstrated higher levels of nurturance, emerging adults still had positive outcomes as seen in Maternal Mitigation; higher levels of maternal nurturance serve as a mitigating factor from the lower levels of paternal nurturance with moderate psychological control. Manzeske and Dopkins Stright (2009), Rodriguez et al. (2016), and Beyers and Goossen (2008) discussed similar results; maternal nurturance had a greater, positive influence on emerging adult development.

The second hypothesis was also partially supported. It was hypothesized that parenting profiles with high psychological control would result in lower exploration and commitment and higher rumination and use of suppression. The Parental Repression profile, characterized by the highest levels of parental psychological control and lowest levels of nurturance, resulted in the highest levels of: ruminative exploration, use of suppression, and lowest levels of commitment and in-depth exploration. Luyckx et al. (2007) also found that parental psychological control leads to feelings of shame and doubt when making important decisions for identity development (Gomes Cordeiro et al., 2018). Emerging adults are less capable of managing their emotions, making them susceptible to anxiety and depression (Manzeske \& Dopkins, 2009; McKinney \& Renk, 2008). 
Parental Equivocation is a unique parenting profile in this research, consisting of high levels of parental psychological control and nurturance. Psychological control from both parents seemed to be a greater influence on negative identity development and emotional self-regulation despite the high levels of parental nurturance. Manzeske \& Dopkins (2009) had similar findings; despite mothers being affectionate towards their children, the higher levels of psychological control still resulted in poorer outcomes for emerging adults.

\section{Limitations}

A threat to internal validity was the risk of self-report bias from participants; they may alter responses to avoid scrutiny (Althubaiti, 2016). Some threats to external validity include difficulty in generalizing the results to non-college attending emerging adults and more diverse populations (61.9\% of the participants identified as White and 69.9\% identified as females). Despite the parenting profiles being congruent with other research, replication of the study is needed to assess if the profiles are consistent and applicable for other populations.

\section{Conclusions}

The results of this study contributed to existing research by further examining parenting and emerging adulthood developmental outcomes. This research brings two unique parenting profiles to the field of knowledge, Maternal Mitigation and Parental Equivocation. They challenge common themes in parenting by accentuating the influence of differing levels of nurturance and psychological control from one or both parents. Future research is still required for examining additional domains of parenting and evaluating other samples of emerging adults to continue to understand the complexities of parenting.

\section{Acknowledgements}

I would like to express my gratitude to the professors in the Family, Youth and Community Sciences department that have contributed to my enriching undergraduate studies and research experience. I would like to especially recognize Dr.Forthun for his patience, expertise, and guidance as my thesis advisor. I would also like to thank my family for their unconditional support during my research and thesis experience. I am also grateful for the research opportunities the University of Florida has given me to further pursue my goals. 


\section{References}

Althubaiti, A. (2016). Information bias in health research: Definition, pitfalls, and adjustment methods. Journal of Multidisciplinary Healthcare, 9, 211-217. doi:http://dx.doi.org/10.2147/JMDH.S104807

Arnett, J.J., (2015). Emerging Adulthood: The Winding Road from the Late Teens Through the Twenties ( $2^{\text {nd }}$ ed.). Oxford, NY: Oxford University Press.

Barber, B.K. (1996). Parental Psychological Control: Revisiting a Neglected Construct. Child Development, 67(6), 3296-3319. https://doi.org/10.1111/j.1467-8624.1996.tb01915.x

Baumrind, D. (1971). Current patterns of parental authority. Developmental Psychology, 4(1, Pt.2), 1-103. http://dx.doi.org/10.1037/h0030372

Beyers, W., \& Goossen, L. (2008). Dynamics of perceived parenting and identity formation in late adolescence. Journal of Adolescence, 31(2), 165-184. https://doi.org/10.1016/j.adolescence.2007.04.003

Beyers, W., \& Luyckx, K. (2016). Ruminative exploration and reconsideration of commitment as risk factors for suboptimal identity development in adolescence and emerging adulthood. Journal of Adolescence, 47(SI), 169-178. https://doi.org/10.1016/j.adolescence.2015.10.018

Castillo, L.G., \& Schwartz, S.J. (2013) Introduction to the Special Issue on College Student Mental Health. Journal of Clinical Psychology, 0(0), 1-7. DOI: 10.1002/jclp.21972

Cohen, J. (1988). Statistical Power Analysis for the Behavioral Sciences. New York, NY: Routledge Academic.

Erikson, E.H. (1950). Childhood and Society. New York, NY: W.W. Norton \& Co.

Finley, G., \& Schwartz, S. (2004). The father involvement and nurturant fathering scales: Retrospective measures for adolescent and adult children. Educational and psychological measurement, 64(1), 143-164. https://doi.org/10.1177/0013164403258453

Garcia, O.F., \& Serra, E. (2019). Raising Children with Poor School Performance: Parenting Styles and Short- and Long-Term Consequences for Adolescent and Adult Development. International Journal of Environmental Research and Public Health, 16(7), 1089. https://doi.org/10.3390/ijerph16071089

Gomes Cordeiro, P.M., Paixão, M.P., Lens, W., Lacante, M., \& Luyckx, K. (2018). Parenting Styles, Identity Development, and Adjustment in Career Transitions: The Mediating Role of Psychological Needs. Journal of Career Development, 45(1), 83-97. https://doi.org/10.1177/0894845316672742

Gross, J. J., \& John, O. P. (2003). Individual differences in two emotion regulation processes: 
Implications for affect, relationships, and well-being. Journal of Personality and Social Psychology, 85(2), 348-362. doi:10.1037/0022-3514.85.2.348

Henry, D. B., Tolan, P. H., \& Gorman-Smith, D. (2005). Cluster analysis in family psychology research. Journal of Family Psychology : JFP : Journal of the Division of Family Psychology of the American Psychological Association (Division 43), 19(1), 121-

132. https://doi.org/10.1037/0893-3200.19.1.121

Luyckx, K., Soenens, B., Vansteenkiste, M., Goossens, L., \& Berzonsky, M. D. (2007). Parental psychological control and dimensions of identity formation in emerging adulthood. Journal of Family Psychology, 21(3), 546-550. http://dx.doi.org/10.1037/0893-3200.21.3.546

Manzeske, D.P., \& Dopkins Stright, A. (2009). Parenting Styles and Emotion Regulation: The Role of Behavioral and Psychological Control During Young Adulthood, 16, 223-229. https://doi.org/10.1007/s10804-009-9068-9

Marcia, J. E. (1966). Development and validation of ego-identity status. Journal of Personality and Social Psychology, 3(5), 551-558. https://pdfs.semanticscholar.org/f145/f3fbada1 eb7a01052255f586094301669287.pdf

Magnusson, D., \& Stattin, H. (2006). The Person in Context: A Holistic-Interactionistic Approach. In R. M. Lerner \& W. Damon (Eds.), Handbook of child psychology: Theoretical models of human development (pp. 400-464). Hoboken, NJ, US: John Wiley \& Sons Inc.

McKinney, C., \& Renk, K. (2008). Differential Parenting between Mothers and Fathers: Implications for Late Adolescents. Journal of Family Issues, 29(6), 806-827. http://dx.doi.org/10.1177/0192513X07311222

Nelson, L. J., Padilla-Walker, L., Christensen, K. J., Evans, C. A., \& Carroll, J. S. (2011). Parenting in emerging adulthood: An examination of parenting clusters and correlates. Journal of Youth and Adolescence, 40(6), 730-43. doi:http://dx.doi.org/10.1007/s10964-010-9584-8

Pallant, J. (2016). SPSS Survival Manual. New York, NY: McGraw Hill.

Ramsey, P. H., \& Ramsey, P. P. (2009). Power and type I errors for pairwise comparisons of means in the unequal variances case. The British Journal of Mathematical and Statistical Psychology, 62, 263-281. doi:http://dx.doi.org/10.1348/000711008X291542

Rodriguez, C. M., Tucker, M. C., \& Palmer, K. (2016). Emotion regulation in relation to emerging adults' mental health and delinquency: A multi-informant approach. Journal of Child and Family Studies, 25(6), 1916-1925. doi:http://dx.doi.org/10.1007/s10826-015-0349-6

Ward, J. H. (1963). Hierarchical grouping to optimize an objective function. Journal of the American Statistical Association, 58(301), 236. DOI: 10.2307/2282967

Zong, X., Cheah, C.S.L., Yu, J., Lim, H.M., Vu, K.T.T., \& Opara, N. (2019). Identity Synthesis as a Pathway Linking Parenting and Emerging Adults' Internalizing Problems. Journal of Child and Family Studies, 28(4), 1029-1041. https://doi.org/10.1007/s10826-019-01330-x 